\title{
Salon
}

\section{W is for Wilbert's wee willy (which tends to go off prematurely)}

Alan Cassels, the author of The ABC's of Disease Mongering, discusses the letter $\mathrm{W}$, wondering if pill makers are a wee bit premature in touting their latest disease.

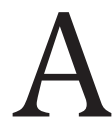
$\mathrm{s}$ a frequent lecturer on pharmaceutical issues I learned very early that you can't talk about drugs without at least one erectile dysfunction joke. Hear the one about Viagra being marketed in liquid form? Now it's truly possible for a man to pour himself a "stiff one." Badum-bum.

If you found that funny, you're not keeping up. Viagra jokes are passé.

Move over ED, welcome PE.

Yes, I'm talking about premature ejaculation, the hottest new disease to (almost) hit the comedy circuit.

But, whoa, not so fast ...

It seems the makers of this new treatment for PE suffered from a bit of premature enthusiasm themselves. Back in late 2005, Johnson \& Johnson was told by the US Food and Drug Administration that dapoxetine, their exciting new drug for PE and similar to any other SSRI antidepressants was "not approvable." Dang. Even though dapoxetine "increased intravaginal ejaculatory latency (IEL) time" better than placebo, according to two, I2-week phase III randomized, placebo-controlled studies, the FDA gave them the big thumbs down. Why?

The researchers were told to keep testing. I'll buy that because the delay gives us guys some time to brace ourselves for the inevitable marketing attack on our insecure sexual selves.

You see, dapoxetine had the number crunchers worked into a froth because the potential PE market is massive. Not like the wimpy market for ED drugs, a condition that affects only about I0\%-I $2 \%$ of men. PE may affect as many as $30 \%-40 \%$ of us guys - many of whom will soon be begging for a branded pharmaceutical enhancement.

Some naysayers have already been trotting out their tired clichés, calling the medicalization of the male orgasm another crude incarnation of "selling sickness," namely, pitching drugs for new make-believe diseases. But I'd never say that.

At the extreme end of the spectrum, there are some men who are so triggerhappy their pistols go off in the holster. And those men need whatever help we can give them. Doctors know that the SSRIs like fluoxetine and paroxetine delay ejaculation in men and dampen sexual interest in women (among other pesky side effects), so what's wrong with taking advantage of their "darker" sides?

Speaking of which, in terms of the sexual-dampening effect of SSRIs, there's a friend of mine who constantly jokes about her overactive libido. She likes to brag about how her antidepressant "brings her back to normal" in terms of how often she wants to shag her husband. Seems Gord isn't arguing. Her decreased sexual desire means he can spend more time in the garden. They're both happier. Sometimes less IS more.

But for us guys, thank goodness there'll soon be a brand new, repackaged condition, and a brand name drug loaded with marketing mojo ready to take it on. I can already picture the ads targeting every gun-slinging dude on the planet (which is all of us) with buff guys staring at their stopwatches, with big satisfied smiles pasted on their faces and a tagline shouting: "Wanna go a little longer?" C'mon who can say no to that?

The kicker, of course, is that only men will be urged to answer those questions. And that fact brings us to the one little problem in the marketing plan for PE: how on earth will we ever agree on what constitutes "premature"? Maybe the concept of "premature," be it 30 seconds, 5 minutes or half an hour, rests in the eye of the beholder? And maybe what a guy thinks is "premature" may be "just long enough" or even "perfect" for his partner. It might even be too long.

But let's not muddy the marketing

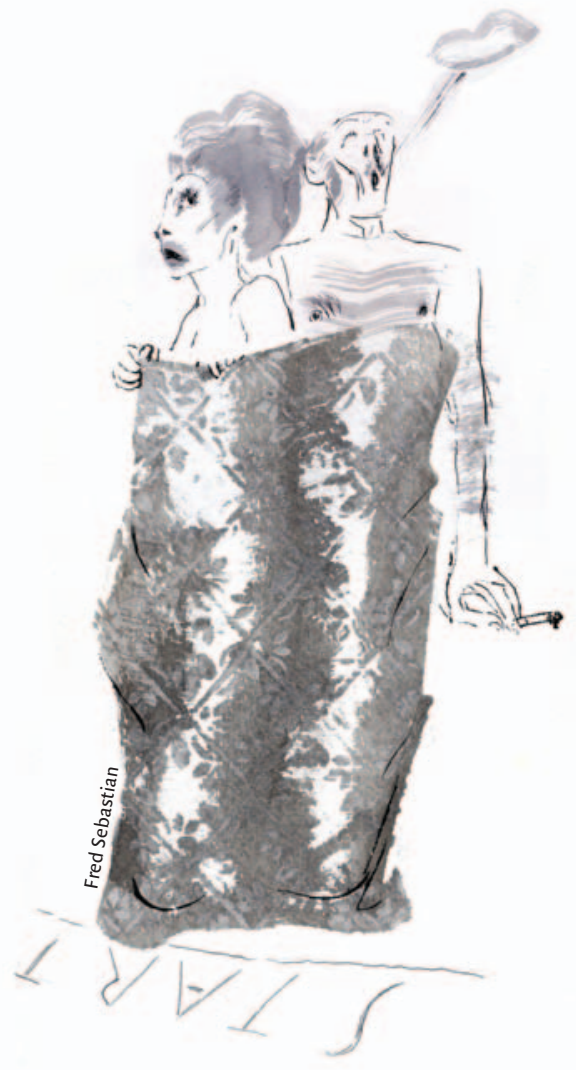

moment by focusing on the duration of "the act." Let's just hope our partners don't ask too many questions and otherwise disrupt what will likely be the best event in stand-up comedy to hit the stage in a long, long time.

\section{Alan Cassels BA MPA}

Alan Cassels is a drug policy researcher at the University of Victoria. His new book, The ABC's of Disease Mongering, a Guide to Drugs and Disorders, is due in October 2007.

We encourage you to post your views on this article at cmaj.ca. Contributors are encouraged to read our online guidelines and send their submission (70o words maximum, French or English language) to salon@cma.ca. 